\title{
Scalp Wound Closures in Mohs Micrographic Surgery: A Survey of Staples vs Sutures
}

\author{
Brett C. Neill, MD; Edward W. Seger, MD, MS; Jace J. Rickstrew, MD; Anand Rajpara, MD;
} Thomas L.H. Hocker, MD

\section{PRACTICE POINTS}

- Scalp wounds present a unique challenge for closure during Mohs micrographic surgery due to the scalp's tendency to bleed, limited elasticity, and hair-bearing nature.

- Among fellowship-trained Mohs surgeons, scalp wounds were closed with staples more often than with epidermal sutures.

- Staples and sutures for scalp wounds were perceived to be equivalent in risk of complications, cosmetic outcome, and overall patient satisfaction.

- Compared to epidermal sutures, staples were perceived as advantageous in high-tension areas and for speed of closure.

Limited data exist comparing staples and sutures for closing scalp wounds during Mohs micrographic surgery (MMS). We surveyed practicing Mohs surgeons who were members of the American College of Mohs Surgery (ACMS) on their scalp wound closure preferences as well as the clinical and economic variables that impact their decisions. Comparisons were made between current practice habits, preferences, and provider demographics. Sixty-eight ACMS fellowship-trained Mohs surgeons completed the survey. Overall, scalp wounds during MMS were most frequently closed using staples.

Cutis. 2020;106:96-99. imited data exist comparing staples and sutures for scalp closures during Mohs micrographic surgery (MMS). As a result, the closure method for these scalp wounds is based on surgeon preference without established consensus. The purpose of this study was to survey practicing Mohs surgeons on their scalp wound closure preferences as well as the clinical and economic variables that impact their decisions. Understanding practice habits can guide future trial design, with a goal of creating established criterion for MMS scalp wound closures.

\section{Methods}

An anonymous survey was distributed from April 2019 to June 2019 to fellowship-trained Mohs surgeons using an electronic mailing list from the American College of Mohs Surgery (ACMS). The 10-question survey was approved by the University of Kansas institutional review board and the executive committee of the ACMS. Surgeons were asked about their preferred method for scalp wound closure as well as clinical and economic variables that impacted those preferences. Respondents indicated their frequency of using deep sutures, epidermal sutures, and wound undermining on a sliding scale of $0 \%$ to $100 \%$. Comparisons were made between practice habits, preferences, and surgeon demographics using $t$ tests. Statistical significance was determined as $P<.05$.

From the Division of Dermatology, University of Kansas Medical Center, Kansas City.

The authors report no conflict of interest.

Correspondence: Brett C. Neill, MD, Division of Dermatology, University of Kansas Medical Center, 3901 Rainbow Blvd, Kansas City, KS 66160 (bcneill6@gmail.com).

doi:10.12788/cutis.0039 


\section{Results}

Sixty-eight ACMS fellowship-trained Mohs surgeons completed the survey. The average age of respondents was 45 years; $69.1 \%(n=47)$ of respondents were male, and $76.5 \%(\mathrm{n}=52)$ practiced in a private setting (Table 1$)$. Regardless of epidermal closure type, deep suture placement was used in an average (standard deviation [SD]) of $88.8 \%(19.5 \%)$ of cases overall, which did not statistically differ between years of Mohs experience or practice setting (Table 2). Wound undermining was performed in an average (SD) of $83.0 \%(24.3 \%)$ of cases overall and was more prevalent in private vs academic settings (87.6\% [17.8\%] vs $65.7 \%$ [35.0\%]; $P<.01)$. Epidermal sutures were used in an average (SD) of $27.1 \%$ (33.5\%) of scalp wound cases overall. Surgeons with less experience ( $\leq 5$ years) used them more frequently (average [SD], 42.7\% [36.2\%] of cases) than surgeons with more experience ( $\geq 16$ years; average [SD], $18.8 \%$ [32.6\%] of cases; $P=.037$ ). There was no significant difference between epidermal suture placement rates and practice setting (average [SD], $18.1 \%$ [28.1\%] of cases for academic providers vs 30.0\% [34.8\%] of cases with private providers; $P=.210$ ).

\section{TABLE 1. Demographics of Surveyed Mohs Micrographic Surgeons $(\mathrm{N}=68)$}

\begin{tabular}{ll} 
Demographic & Response \\
\hline Gender, $\mathrm{n}(\%)$ & $47(69.1)$ \\
\hline Male & $21(30.9)$ \\
\hline Female & $45(9)$ \\
Average age, $\mathrm{y}(\mathrm{SD})$ & $68(100)$ \\
Fellowship trained, $\mathrm{n}(\%)$ & \\
Practice setting, $\mathrm{n}(\%)$ & $6(8.8)$ \\
\hline Private, solo & $18(26.4)$ \\
\hline Private, small group & $28(41.2)$ \\
\hline Private, large group & $16(23.5)$ \\
\hline Academic & \\
Years of Mohs experience, $\mathrm{n}(\%)$ & \\
$\leq 5$ & $20(29.4)$ \\
\hline $6-15$ & $26(38.2)$ \\
\hline$\geq 16$ & $22(32.4)$ \\
\hline
\end{tabular}

Abbreviation: SD, standard deviation.
Clinical and economic factors that were most important during wound closure were ranked (beginning with most important) as the following: risk of complications, cosmetic outcome, hair preservation, patient comfort during closure, healing time, and closure cost. In all demographic cases, risk of complications was ranked 1 or 2 (1=most important; $6=$ least important) overall; cost was the least important factor overall (Table 2).

Surgeons perceived staples to be superior for speed of closure and for closing wounds in high-tension areas, whereas sutures were perceived as superior when considering cost of closure and ease of removal (Table 3). Successful healing rate, healing time, hair preservation, overall cosmetic outcome, and lower risk of complications were viewed as equivalent when comparing staples and sutures.

In cases in which surgeons did not use staples for closure, the most important factors for opting to not use them were patient discomfort $(52.9 \%[n=36])$, cost $(25.0 \%[\mathrm{n}=17])$, and worse overall cosmetic outcome $(23.5 \%[n=16])$ (Table 4). The most frequent locations outside of scalp wounds that physicians considered the use of staples for closure were the back $(19.1 \%[n=13])$, thigh $(10.3 \%[n=7])$, and shoulder $(8.8 \%[n=6])$.

\section{Comment}

Epidermal closure with sutures was reportedly used in an average of only $27.1 \%$ of scalp wound cases, with clinical factors such as cosmetic outcome, risk of complications, and closure time seen as either equivalent or inferior to staples. Our data suggest that surgeon closure perceptions generally are in agreement with established head and neck literature within different medical specialties that favor staple closures, particularly in high-tension areas. ${ }^{1}$ Interestingly, the most common reasons given for not using staples included patient discomfort, cost, and worse cosmetic outcomes, which are unsubstantiated with head and neck comparative studies. $^{2-4}$

Although cost was the least important variable for determining closure type in our surveyed cohort, it is likely that the overall cost of closure is frequently underestimated. A higher material cost is noted with staples; however, the largest determinant of overall cost remains the surgeon's time, which is reduced by factors of 10 or more when closing with staples., ${ }^{2,3}$ This difference-coupled with the unchanged cosmetic outcome and complication rates-makes staples more advantageous for high-tension scalp wounds. ${ }^{4}$ Moreover, the stapling technique is more reproducible than suturing, which requires more surgical skill and experience.

Limitations of this study include a lack of directly comparable data for staple and suture scalp wound closures. In addition, the small cohort of respondents in this preliminary study can serve to guide future studies. 
TABLE 2. Physicians' Preferences for Scalp Wound Closure

\begin{tabular}{|c|c|c|c|c|c|c|}
\hline \multirow[b]{2}{*}{ Physician Preferences } & \multirow{2}{*}{$\begin{array}{l}\text { Overall } \\
\text { Consideration } \\
\text { Values }\end{array}$} & \multicolumn{3}{|c|}{ Years of Mohs Experience } & \multicolumn{2}{|c|}{ Practice Setting } \\
\hline & & $\leq 5$ & $6-15$ & $\geq 16$ & Academic & Private \\
\hline \multicolumn{7}{|l|}{$\begin{array}{l}\text { Most important consideration in } \\
\text { wound closure }^{\mathrm{a}}\end{array}$} \\
\hline Risk of complications & 1 & 2 & 1 & 1 & 1 & 1 \\
\hline Cosmetic outcome & 2 & 1 & 2 & 3 & 4 & \\
\hline Hair preservation & 3 & 3 & 3 & 4 & 3 & . \\
\hline Patient comfort during closure & 4 & 5 & 4 & 2 & & 5 \\
\hline Healing time & 5 & 4 & 5 & 5 & & 4 \\
\hline Closure cost & 6 & 6 & 6 & 6 & 6 & 6 \\
\hline $\begin{array}{l}\text { Average (SD) frequency of deep } \\
\text { suture placement, }{ }^{b} \%\end{array}$ & $88.8(19.5)$ & $90.4(16.9)$ & $90.3(18.2)$ & $85.5(23.7)$ & $87.5(17.0)$ & $89.2(20.3)$ \\
\hline $\begin{array}{l}\text { Average (SD) frequency of } \\
\text { undermining wounds, }{ }^{\text {b } \%}\end{array}$ & $83.0(24.3)$ & $86.7(17.6)$ & (23.2) & $76.6(30.5)$ & $65.7(35.0)$ & $87.6(17.8)$ \\
\hline $\begin{array}{l}\text { Average (SD) frequency of } \\
\text { use of sutures for epidermal } \\
\text { closure, }{ }^{b} \%\end{array}$ & 27.1 (33.5) & 42.7 (36.2) & $21.7(29.0)$ & $18.8(32.6)$ & $18.1(28.1)$ & $30.0(34.8)$ \\
\hline
\end{tabular}

Abbreviation: SD, standard deviation.

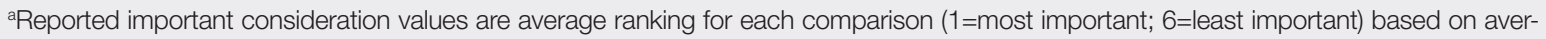
age values provided by respondents.

${ }^{\mathrm{b}}$ Frequency provided by respondents on a sliding scale of $0 \%$ to $100 \%$.

TABLE 3. Surgeon-Perceived Closure Superiority in All Wound Settings $(N=68)$

\begin{tabular}{llll}
\hline Superiority for Each Instance ${ }^{\mathrm{a}}$ & Sutures, $\mathbf{n}(\%)$ & Equivalent, $\mathbf{n}(\%)$ & Staples, $\mathbf{n}(\%)$ \\
\hline Cost & $31(45.6)$ & $27(39.7)$ & $10(14.7)$ \\
\hline Lower complication risk & $10(14.7)$ & $50(73.5)$ & $8(11.8)$ \\
\hline Faster closure & $7(10.3)$ & $11(16.2)$ & $50(73.5)$ \\
\hline Faster healing time & $16(23.5)$ & $45(66.2)$ & $3(10.3)$ \\
\hline Overall cosmetic outcome & $25(36.8)$ & $40(58.8)$ & $2(2.9)$ \\
\hline Patient satisfaction & $40(58.8)$ & $26(38.2)$ & $9(13.2)$ \\
\hline Ease of removal & $38(55.9)$ & $21(30.9)$ & $9(13.2)$ \\
\hline Preservation of hair & $19(27.9)$ & $48(55.9)$ & $8(11.8)$ \\
\hline Highest chance of successful healing & $18(26.5)$ & $22(32.4)$ & $27(39.7)$ \\
\hline High-tension area wound & $19(27.9)$ & & 32.8 \\
\hline
\end{tabular}


SCALP WOUND CLOSURES

TABLE 4. Factors Influencing Surgeons' Decision Not to Use Staples for Scalp Wounds $(\mathrm{N}=68$

\begin{tabular}{ll} 
Reason to Not Use Staples & No. of Respondents (\%) \\
\hline Patient discomfort & $36(52.9)$ \\
\hline Cost & $17(25.0)$ \\
\hline Worse cosmesis & $16(23.5)$ \\
\hline Not trained in use & $9(13.2)$ \\
\hline More complications & $7(10.3)$ \\
\hline Slower healing time & $2(2.9)$ \\
\hline Always use staples & $2(2.9)$ \\
\hline
\end{tabular}

Conclusion

Scalp wounds during MMS were most frequently closed using staples vs sutures, with the perception that these methods are equivalent in complication risk, cosmetic outcome, and overall patient satisfaction. These results agree with comparative literature for head and neck surgery and assist with establishing an epidemiologic baseline for future studies comparing their use during MMS.

REFERENCES

1. Ritchie AJ, Rocket LG. Staples versus sutures in the closure of scalp wounds: a prospective, double-blind, randomized trial. Injury. 1989;20:217-218.

2. Batra J, Bekal RK, Byadgi S, et al. Comparison of skin staples and stancard sutures for closing incisions after head and neck cancer surgery: a double-blind, randomized and prospective study. J Maxillofac Oral Surg. 2016;15:243-250.

3. Kanegaye JT, Vance CW, Chan L, et al. Comparison of skin stapling devices and standard sutures for pediatric scalp lacerations: a randomized study of cost and time benefits. J Pediatr. 1997; 130:808-813.

4. Khan ANGA, Dayan PS, Miller S, et al. Cosmetic outcome of scalp wound closure with staples in the pediatric emergency department: a prospective, randomized trial. Pediatr Emery Care. 2002;18:171-173.

WWW.MDEDGE.COM/DERMATOLOGY

VOL. 106 NO. 2 I AUGUST 202099

Copyright Cutis 2020. No part of this publication may be reproduced, stored, or transmitted without the prior written permission of the Publisher. 